\title{
Value Network Design for Innovations: Developing Alternative Value Network Drafts
} Martin Kage, Marvin Drewel, Jürgen Gausemeier, and Marcel Schneider

\author{
"You are my friends if you do what I command you."
}

John 15:14

\begin{abstract}
Information technology increasingly permeates established products and services, thereby making them "smart". For companies, this trend necessitates new know-how in unknown fields. Hence, traditional manufacturing companies are increasingly forced to cooperate with new players within new value networks. In contradiction to value chains, value networks oftentimes exhibit no clear hierarchies and are characterized by rather weak ties between the participating players. For a company that wants to create smart products or services, the key challenge is arranging the value network such that the customer obtains a unique value while all participants profit from their engagement. In doing so, companies have to find new partners (companies, research institutes, etc.). In this article, we present a methodology to design value networks for innovations, including approaches to identify necessary competences, find suitable partners, and bundle them to powerful alternative value networks.
\end{abstract}

\section{Introduction}

The well-known concepts of value or supply chains do not do justice to describing how value is created in today's complex networks. Whereas traditional value chains have been characterized by strict upstream and downstream relationships, organizations nowadays interact as networked intermediaries (Porter, 1980; Yassine \& Braha, 2003). These networks not only consist of companies; any player such as a research institute can partake in the process of value creation (Fjeldstad \& Ketels, 2006).

Recently, two independent developments have boosted the interest in value networks and have led to a surge in attention for the discipline of value network design:

1. Networked technologies that only function within a network, such as smartphone networks (Breschi \& Malerba, 2005). Today, the integration of networked technologies into established products, like production machines, turns the latter into "smart products" (Hui, 2014; Porter \& Heppelmann, 2014).

2. Technology firms expanding their know-how through R\&D alliances with other technology firms and open (innovation) networks (Granstad \& Sjölander, 1990; Holmstrom \& Roberts, 1998).
By collaborating in value networks, companies enlarge their technological know-how (Sattler et al., 1992; Gausemeier \& Plass, 2014; Sell, 1994), establish an advantage in time (Zentes et al., 2003), address multiple markets (Zentes et al., 2003) and lower costs and barriers of market entry (Sattler et al., 1992; Sell, 1994). For the following reasons, a practitioner would be ill-advised to design the value network for an innovation only after fully developing the innovation:

1. The decision of which role(s) within the network a company occupies automatically predetermines which partners are needed for the remaining roles and how the relationships with these partners should be shaped. When identifying external players for a value network, companies face a notorious lack of reliable information. This is aggravated by the fact that innovations in the context Internet of Things often require cooperation across established industries. The information quality about possible partners will only become more reliable incrementally (Höfer, 1997). Moreover, the decision of which role is to be occupied predetermines which competences the company has to develop internally in the long run. The process to develop these competences takes time and has to be planned ahead early on (Rübbelke, 2016). 


\section{Value Network Design for Innovations}

\section{Martin Kage, Marvin Drewel, Jürgen Gausemeier, and Marcel Schneider}

2. A partner organization can provide valuable knowledge for the innovation itself (i.e., open innovation). The earlier this knowledge is available, the less costly the adaptation of the innovation (Büchel \& Raub, 2002; Ehrlenspiel et al., 2014).

3 . A value network can hardly be imitated by competitors (Kumar, 2004). The sooner an organization starts to identify its partners, the higher are the chances that these partners do not already cooperate with a competing organization.

4. Companies only know their true competitors after identifying which role(s) within the value network they will occupy in the future. Also, only when the roles in the value networks are determined, can search fields for technological foresight be determined. Naturally, this knowledge is needed as early as possible (Gausemeier \& Plass, 2014).

The aim of this article is to present a methodology for the design of a value network in the early stages of the development process of products and services. The salient feature of this methodology is that it does not identify single companies for a specific job but rather allows for bundles of companies to fulfill the imposed requirements. The research question is therefore: What is a methodology that devises different bundles of partner companies to realize external key activities for a business idea?
In the following section, we briefly review the relevant literature. Next, we present our proposed methodology. And finally, we discuss the implications from a practitioner's viewpoint.

\section{Literature Review}

According to Allee (2015), a value network is "a web of relationships that generates economic value and other benefits through complex dynamic exchanges between two or more individuals, groups, or organizations". It visually describes how value is generated for the consumer. What the business model is for the individual organization, the value network is for a set of interacting organizations (Müller-Stevens \& Lechner, 2005). Value networks can either be developed as a consequence of an innovation idea (i.e., innovation pull), but theoretically could also be used as a strategic tool to evaluate entire branches and collaboratively develop innovation ideas (i.e., value network push). This relationship is illustrated in Figure 1, which shows that our approach can be attributed to the innovation pull stream on the left.

When designing value networks for innovations, approaches from two disciplines are naturally of interest: i) value network design and ii) mergers and acquisitions. The following subsections briefly introduce relevant approaches from these disciplines.

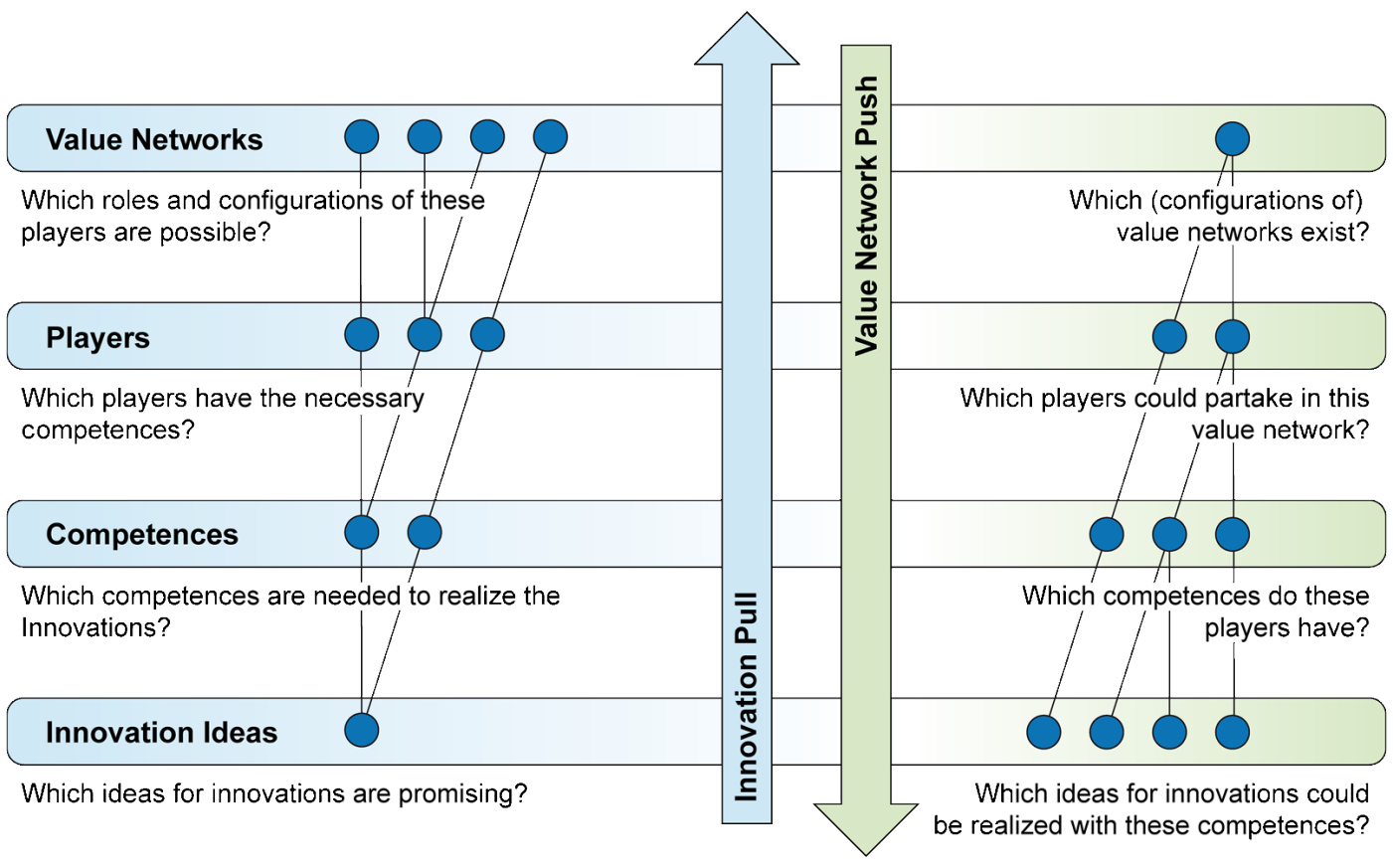

Figure 1. The principles innovation pull and value network push (Heubach et al., 2008; Kraus, 2005) 


\section{Value Network Design for Innovations}

\section{Martin Kage, Marvin Drewel, Jürgen Gausemeier, and Marcel Schneider}

\section{Value network design}

Normann and Ramirez (1993) acknowledged the continuous (re-)design of complex business systems as the key strategic task of successful companies. To differentiate from competitors, organizations need to develop solutions, consisting of products and services, and shape their business system accordingly. An approach that focuses on possible future scenarios has been developed by Kraus (2005). Organizations draft future scenarios and convert them to value potentials. The organization then identifies the roles it wants to occupy in the future value network and can thereby identify the crucially needed strategic assets (Kraus, 2005). A concept to measure and to generate value within a network that includes tangible as well as intangible components has been provided by Möller (2006). The approach contains the timeframe, arrangement, and content of value generating networks. Deutskens (2014) devised a decision model to configure the creation of value for disruptive innovations. The model provides concrete guidance to design the way an organization creates value for disruptive innovations. The principle of value network push has also been brought up by Müller-Stevens and Lechner (2005); they identified six basic maneuvers organizations can use to (re-)shape their value network (Figure 2).

The manoeuvres can be distinguished along the axes Value Network Configuration and Value Network Cover- age (Müller-Stevens \& Lechner, 2005). The potential of each manoeuvre cannot be calculated across-the-board (Deutskens, 2014). The manoeuvres however very nicely depict that value networks are not just a mere consequence of a product, service, or business model and can in fact be used as a strategic tool to actively shape a company's future.

\section{Mergers and acquisitions}

As pointed out above, the configuration of value networks requires laying out the cooperation between companies. That is why, naturally, approaches from mergers and acquisitions are relevant.

Essential basic knowledge about strategic alliances and networks and how they can be designed is provided by Zentes, Swoboda and Morschett (2003). On a much more detailed level, Höfer (1997) developed partner profiles that can be used to evaluate a single organization, according to a certain cooperation scenario. The profiles contain a partner's strategic as well as the cultural fit. Once a possible partner organization needs to be identified, various possibilities are available. Sattler and colleagues (1992) provide a general view of these possibilities. Approaches to plan, conduct, and integrate a partner organization within a merger or an acquisition are provided by Picot (2002) and Jansen (2001). The general idea of their approaches can be adapted to the process of identifying partners.
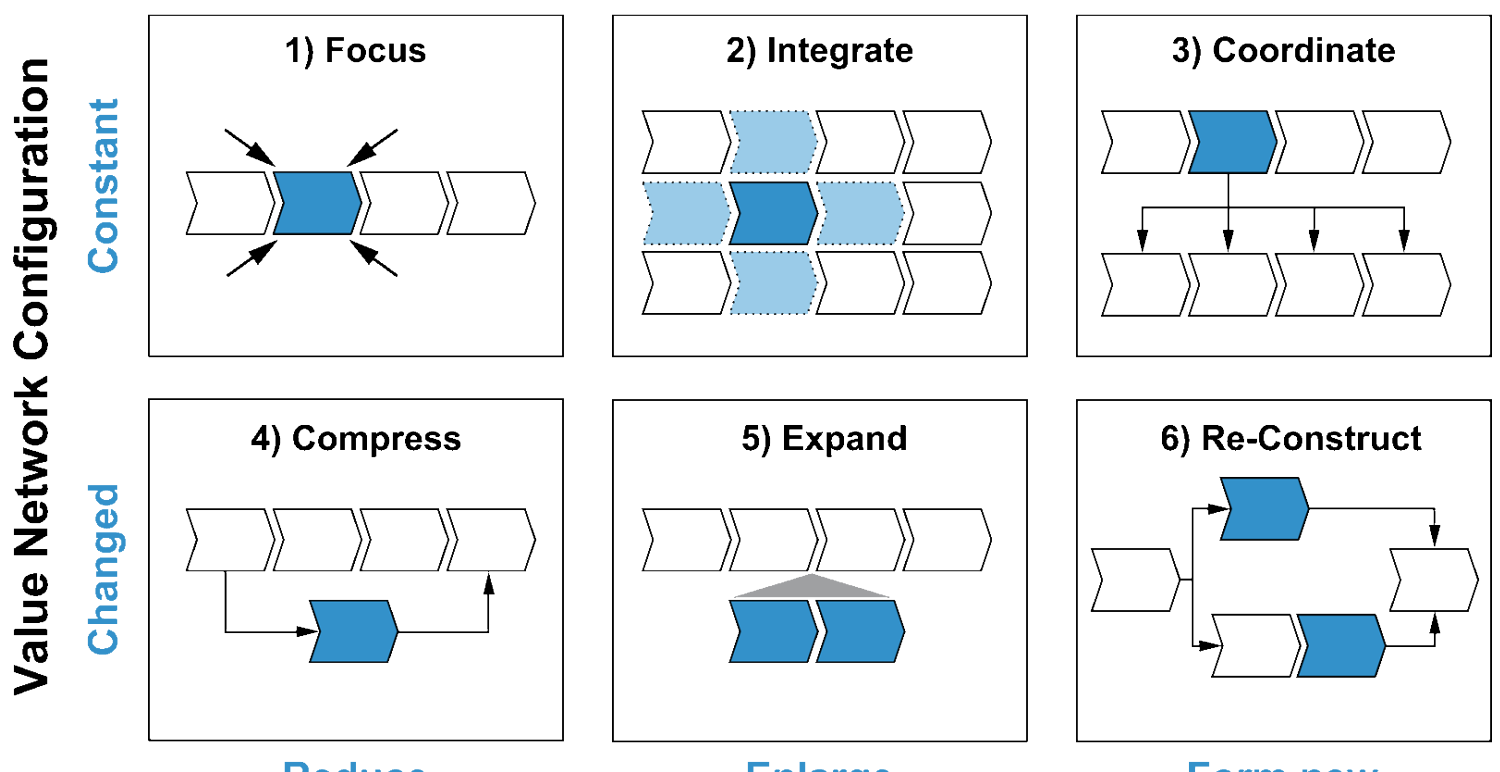

Reduce

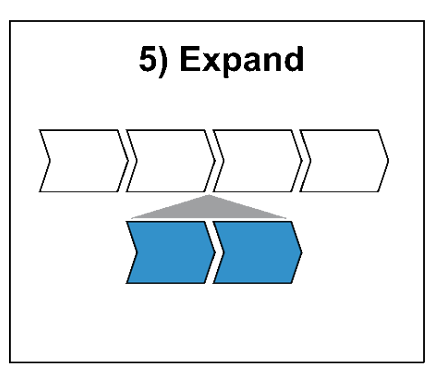

Enlarge

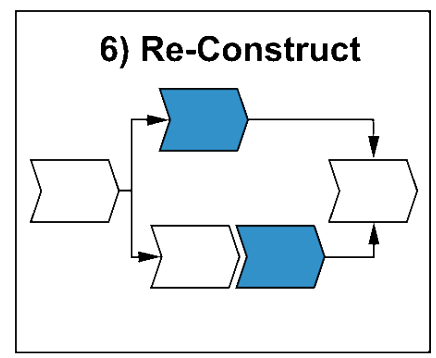

Form new

Value Network Coverage

Figure 2. Value network manoeuvres (according to Müller-Stevens \& Lechner, 2005) 


\title{
Value Network Design for Innovations
}

\author{
Martin Kage, Marvin Drewel, Jürgen Gausemeier, and Marcel Schneider
}

\section{Methodology for Value Network Design for Innovations}

As introduced above, ample theory on value network design and mergers and acquisitions has been published. However, the presented methods and approaches fall short of addressing the following challenges:

1. Finding concrete partner organizations. Methods for value network design aid in arranging the general streams of a value network, however they offer little help for the identification of concrete partners. Oftentimes they also focus on partner companies, although partners in value networks might also be complementarians.

2. Creating different options for the design of value networks. The well-known methods from mergers and acquisitions offer concrete advice on how to find partners for a concrete competence gap and in which ways to engage in a partnership with them. But, they fail to allow for the identification of bundles of partners to fill in a competence gap.

Our methodology to bridge this gap consists of four phases, or milestones, as presented in Figure 3: i) determination of cooperation demand, ii) partner pre-selection, iii) partner evaluation, and iv) implementation planning. We will next discuss each of these four phases

\section{Phases/Milestones}

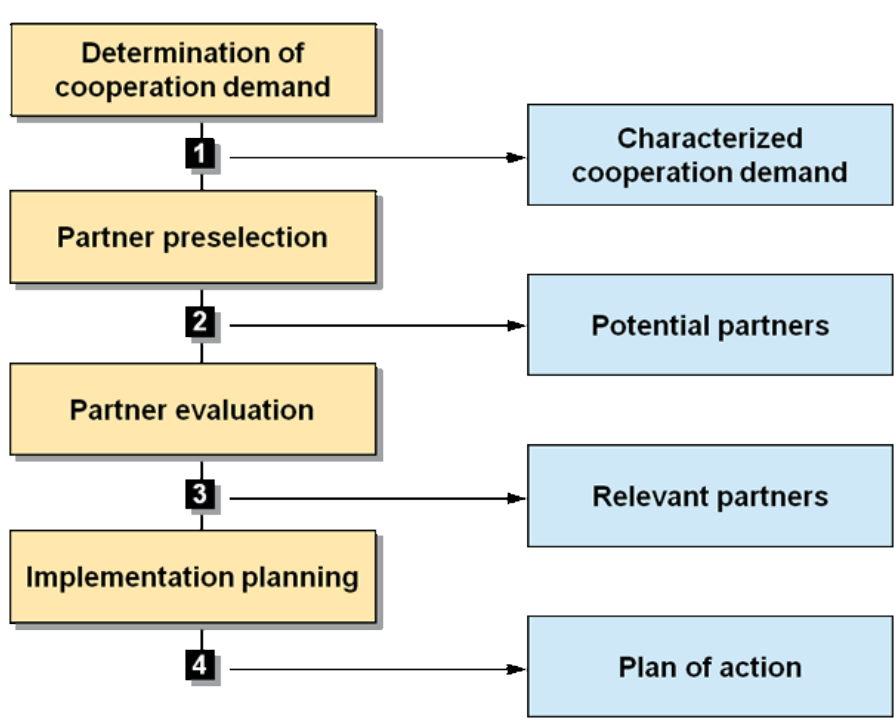

Figure 3. Methodology for designing value networks for innovation of the methodology, which has been validated in projects with a medium-sized German household appliance manufacturing company. In this article, the company name has been anonymized to H.A.M.

\section{Phase 1: Determination of Cooperation De- mand}

H.A.M. is looking at ways of improving the marketability of their kitchen appliances. The company currently prioritizes innovations from the search field Internet of Things, due to the Internet of Things changing the way customers interact with household appliances in the "Smart Home" (Esche \& Henning-Thurau, 2014; Gartner, 2015). From their current innovation ideas, one idea is considered especially promising. Called "Recipe2U", the idea is to link the company's appliances to an online platform that coordinates the delivery of fresh ingredients according to specific dishes the consumer wishes to make. H.A.M.'s kitchen appliances would offer the ability to download specific programs to optimally prepare the ingredients.

Recipe2U requires certain competences, which H.A.M. does not feature at the moment. These required competences are indicated in the lower left corner of Figure 4 . These competences were identified in a preliminary functional decomposition of the planned innovation (Figure 5). We have found that this preliminary functional decomposition works for product, process, and business model ideas in the earlier stages of the innovation process.

The analysis of the functional decomposition revealed six competences. These competences can either be provided by H.A.M. or by a potential partner. For each competence, a decision of whether to develop it inhouse or to obtain it from an external partner has to be made. For that purpose, the strategic relevance and the relative level of each competence are rated. The strategic relevance describes the future importance of a competence. The relative level of competence qualifies how effortful it would be to develop a certain competence in-house. A relatively low strategic relevance and a low relative level of competence result in a high degree of externalization. Competences with these characteristics should therefore be acquired externally. On the other hand, competences with a high importance in the future and thereby a high strategic relevance, combined with an appropriate relative level of competence, result in a low degree of externalization and should therefore be developed internally. The results are visualized in a bubble chart (Figure 6). 


\section{Value Network Design for Innovations}

\section{Martin Kage, Marvin Drewel, Jürgen Gausemeier, and Marcel Schneider}

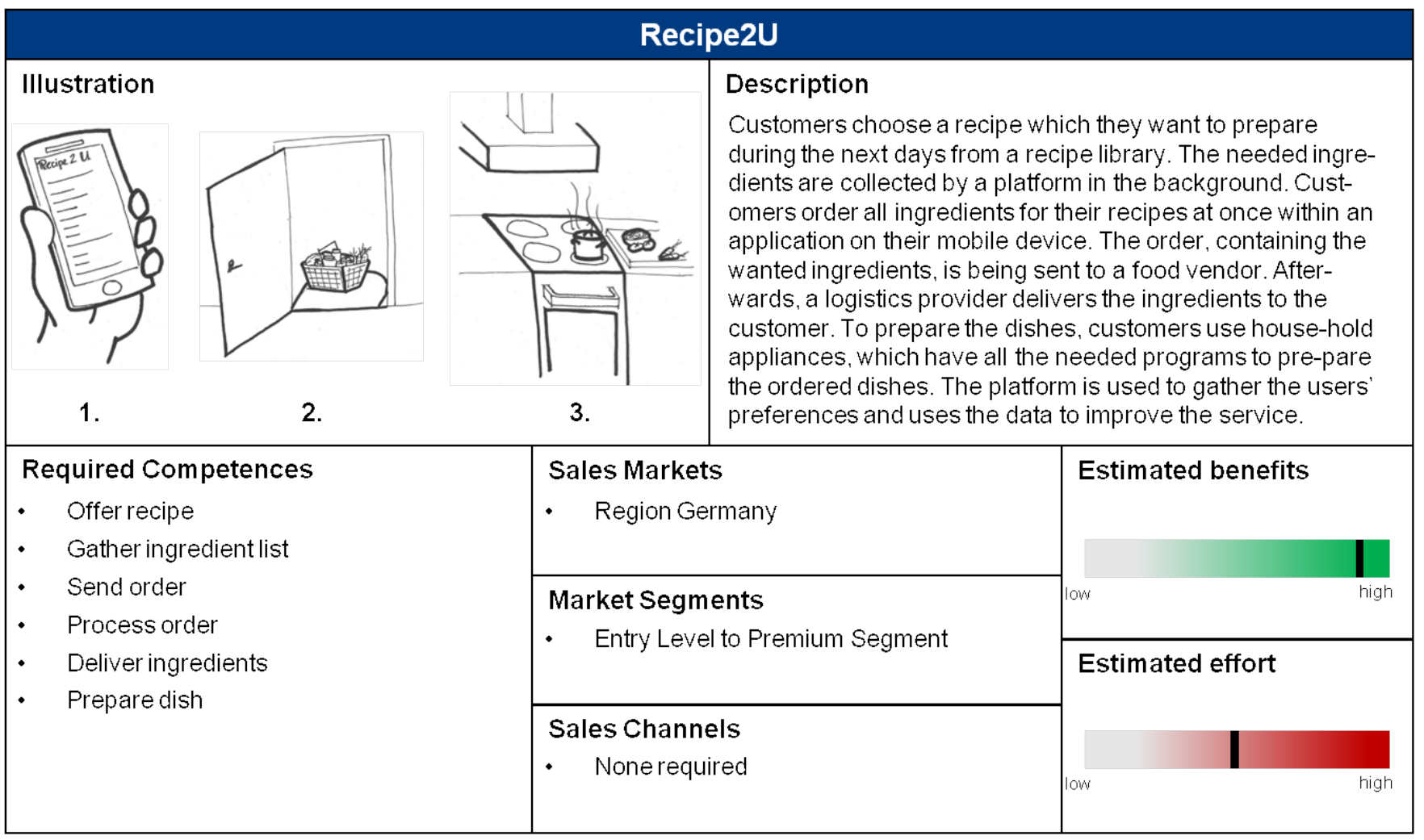

Figure 4. Innovation profile of the Recipe2U business idea
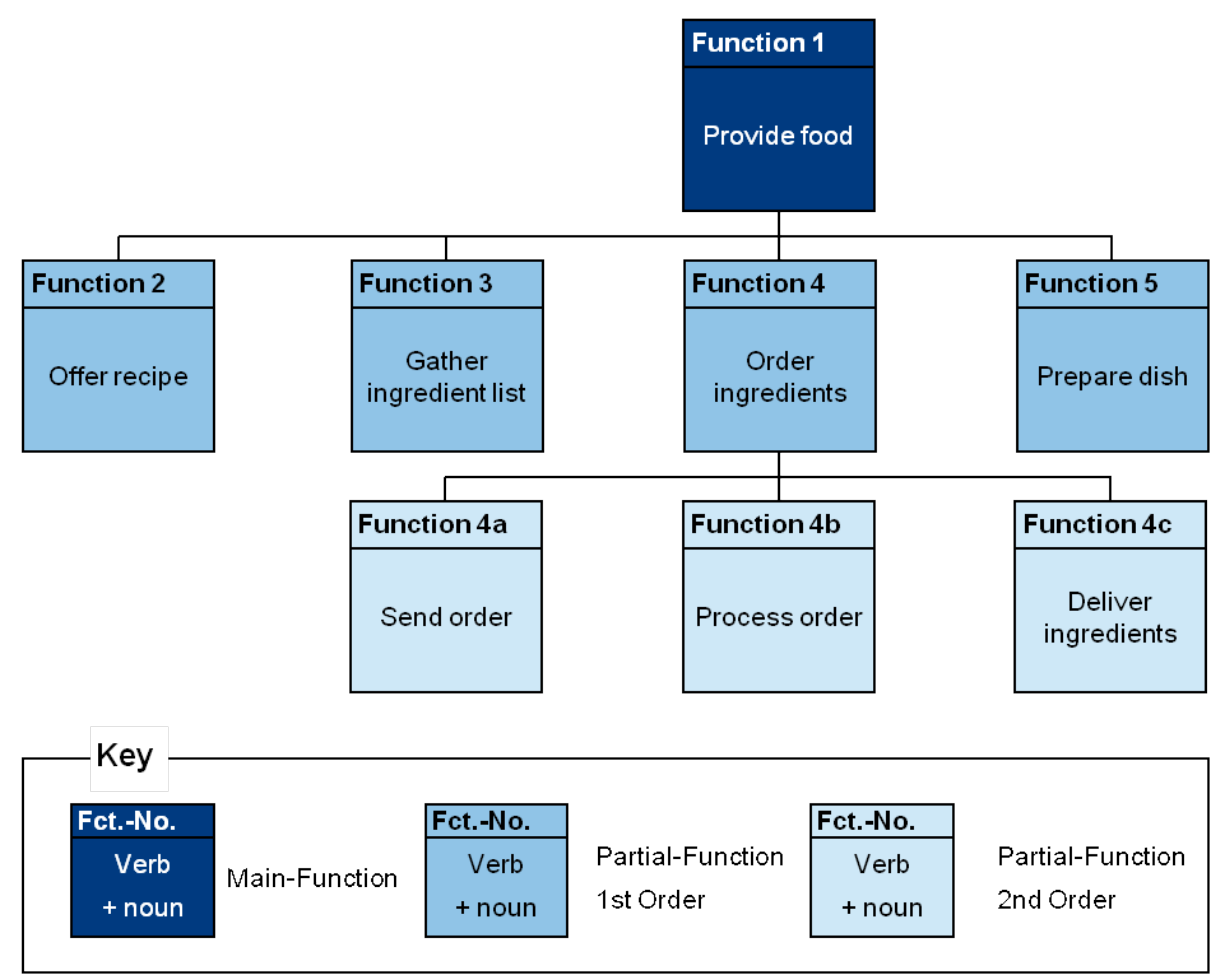

Figure 5. Functional decomposition of the Recipe2U business idea 


\section{Value Network Design for Innovations}

\section{Martin Kage, Marvin Drewel, Jürgen Gausemeier, and Marcel Schneider}

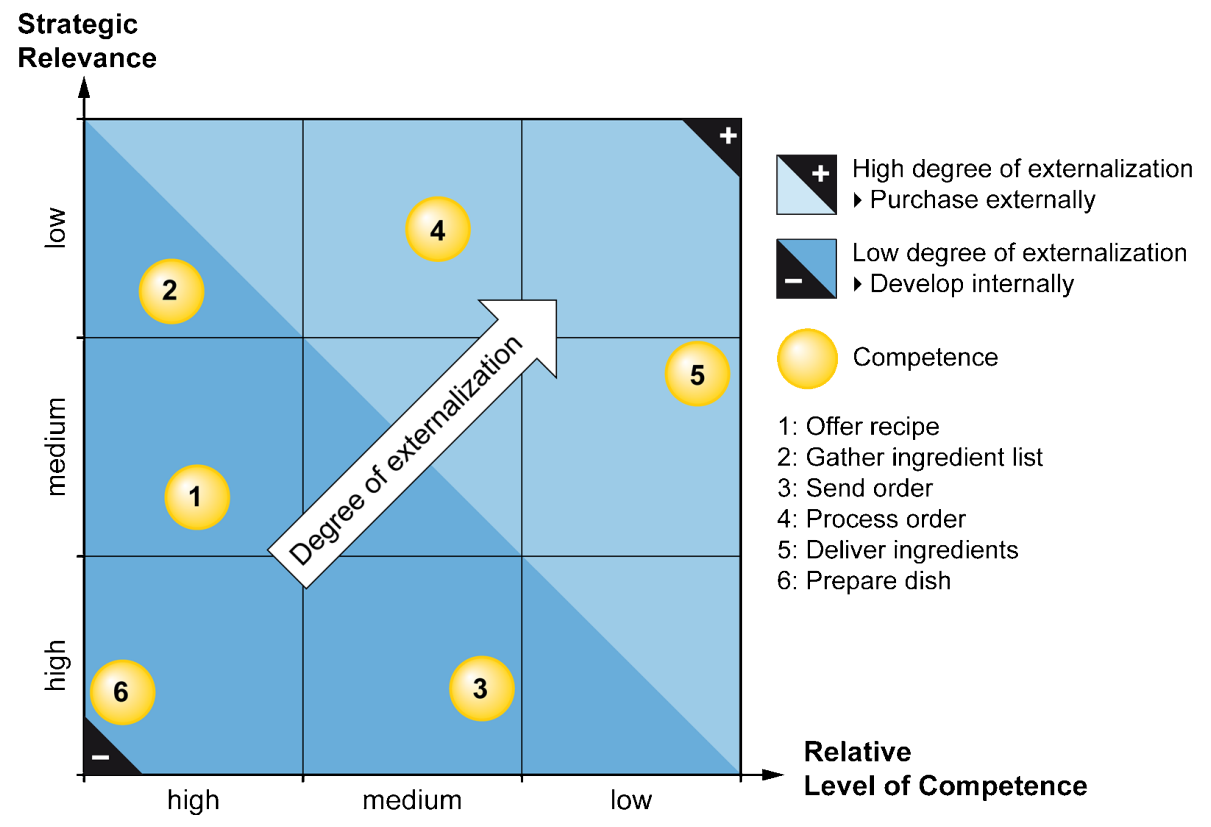

Figure 6. Externalization portfolio for the Recipe2U business idea (according to Hermes, 1995)

In our case, six competences are necessary for the Recipe2U business idea. As Figure 6 indicates, two of these should be provided by external partners and four should be developed or provided internally. At least partly, the latter four are already available for the company. That is, H.A.M. is looking for an organization that is able to deliver ingredients (Competence 5), by using orders from consumers of H.A.M. products (Competence 4). Both groups of competences are later on needed to evaluate possible partners.

\section{Phase 2: Partner Preselection}

A partner is an external organization providing the competences that are not to be built up internally. A fivestage process adapts the effort to identify the relevant partners accordingly:

\section{Research}

2. Applying knock-out criteria

3. Performance evaluation

4. Attitude evaluation

5. Motivation evaluation

The first two stages are part of the partner preselection; the following phase, partner evaluation, contains stages 3 to 5 . To minimize the effort for the following stages, ineligible partners are eliminated from further consideration at the end of each stage, yielding the partner-selection funnel shown in Figure 7.
Partner profiles are the groundwork for the research into possible partners. They describe which requirements are imposed on the external partners in the value network. Naturally, they are unique for every innovation and have to be adapted accordingly. The partner profile contains the required competences, which can be obtained from the innovation itself (see Figure 4). Also, it contains "soft skills", such as the favoured culture and the partners' organizational structure. Also, the partner profile includes a section that outlines features and competences offered by the searching company, H.A.M.. The reason behind this is that a cooperating party is more likely to engage in a partnership if it is interested in H.A.M.'s competences and features. Generally, a partner profile consists of variables and target characteristics. To determine the weighted importance of each variable, their relevance is rated and converted to a percentage relevance by dividing the single valuation by the sum of all valuations of each section.

Databases, personal contacts, specialist journals, online research, etc. can be used to identify possible partner companies for a cooperative project (Sattler et al., 1992). In the validation project, the project team decided to identify possible partner companies for the Recipe $2 \mathrm{U}$ business idea by online research and by interviewing experts from H.A.M. These experts either know the food-delivery market or have experience with cooperative projects. 


\section{Value Network Design for Innovations}

\section{Martin Kage, Marvin Drewel, Jürgen Gausemeier, and Marcel Schneider}
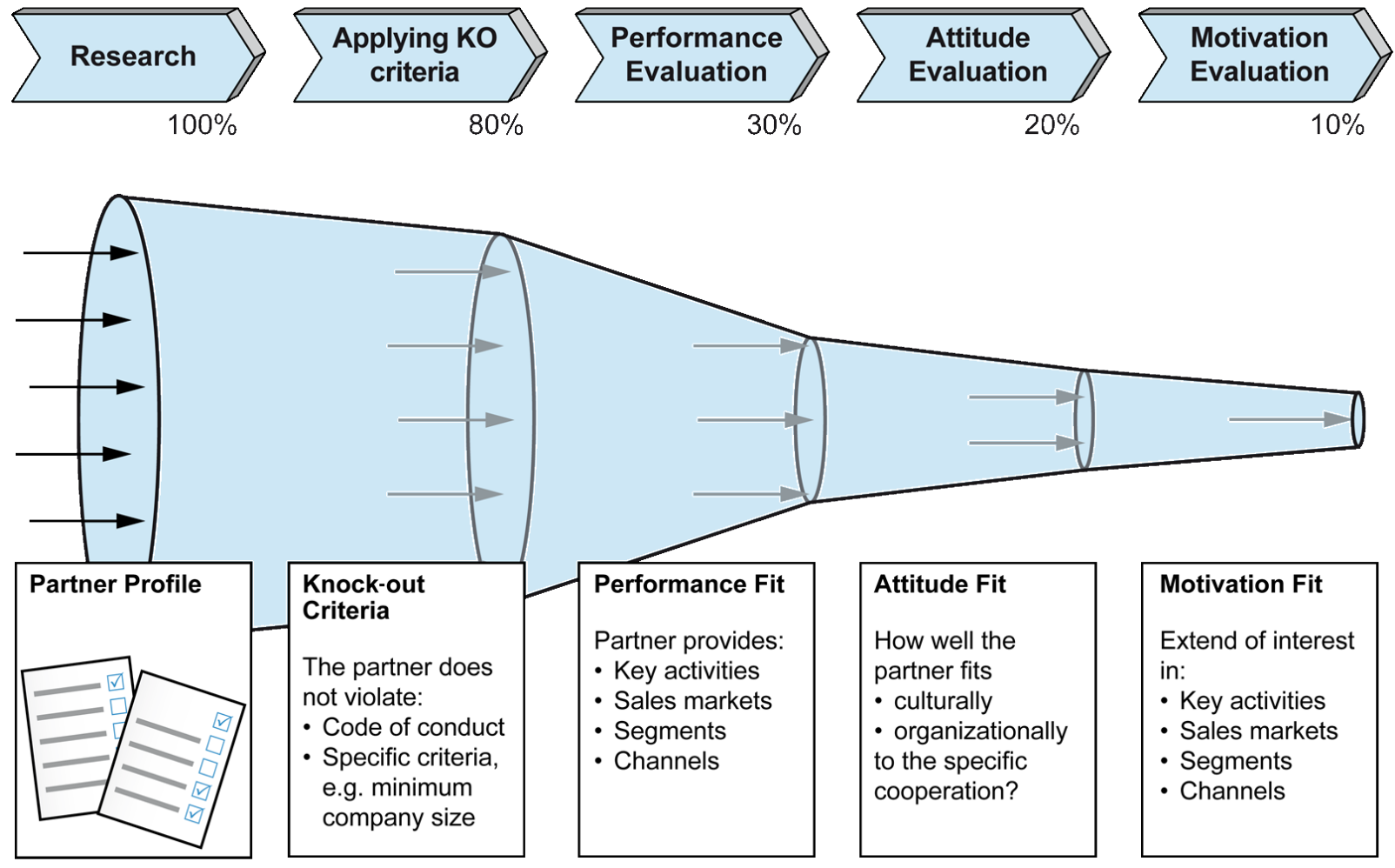

Figure 7. Partner selection process

Once possible partner organizations are identified, knock-out criteria eliminate ineligible companies. Examples of knock-out criteria are the organization's financial status, the existence of hints towards questionable practices, or the size of an organization. These knock-out criteria can be applied to review each partner independently from the innovation (Albrecht, 1994). Optionally, each target characteristic can be selected as a specific knock-out criterion, for example if a minimal size of the partner is required to exclude startups.

\section{Phase 3: Partner Evaluation}

Once knock-out criteria have been applied, the remaining organizations are rated with regard to all variables in the profile. The degree to which an organization fulfills each characteristic is converted to a profile that indicates the percentage fulfillment per section. The result is a performance fit, an attitude fit, and a motivation fit for each potential partner. The final partnership fit combines all three section fits and is the result of the relevance of each section, multiplied by its degree of fulfillment. The gradations of the valuation standard are used to assure that a complete fulfillment results in a high partnership fit (Kühnapfel, 2014). In the valida- tion project, the weighting amounted to $60 \%$ for the performance fit, $25 \%$ for the attitude fit, and $15 \%$ for the motivation fit (Figure 8).

The performance section will be further regarded within the next phase; attitude fit and motivation fit will be used later on. As Weber (1996) states, the attitude of two organizations is important for long-lasting relationships: if a cooperation has to be established in a short amount of time, the motivation fit can be the crucial factor, because a partner organization is more likely to cooperate if it has an intrinsic motivation. An adaptable minimum for the attitude and motivation fits excludes ineligible organizations. These ineligible organizations are not considered for a possible cooperation, because collaborations with these organizations have very low chances for success (Weber, 1996).

\section{Phase 4: Implementation Planning}

As mentioned previously, the performance section contains factors that are necessary to realize the targeted innovation. Oftentimes, only a combination of organizations (i.e., a network) is able to provide all necessary competences. In our validation project, it is very unlikely that just two companies can run a platform, real- 


\section{Value Network Design for Innovations}

\section{Martin Kage, Marvin Drewel, Jürgen Gausemeier, and Marcel Schneider}

\begin{tabular}{|c|c|c|c|c|c|c|}
\hline \multicolumn{2}{|c|}{$\begin{array}{l}\text { Partner Evaluation } \\
\text { Question: } \\
\text { How well does the partner fulfill the required target characteristic? } \\
\text { Valuation standard: } \\
0=\text { no fulfillment at all } \\
1=\text { partial fulfillment } \\
3=\text { largely fulfillment } \\
9=\text { complete fulfillment }\end{array}$} & \multirow{2}{*}{ 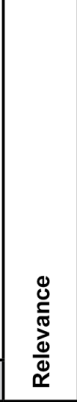 } & \multirow{2}{*}{ 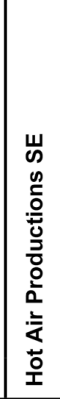 } & \multirow{2}{*}{ 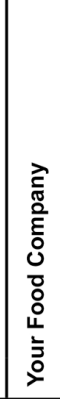 } & \multirow{2}{*}{ 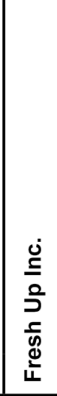 } & \multirow{2}{*}{ 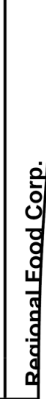 } \\
\hline Variable & Target Characteristic & & & & & \\
\hline \multicolumn{7}{|l|}{ Performance } \\
\hline \multirow{2}{*}{ Needed Competencies } & Process order & $4 \%$ & 9 & 9 & 9 & 9 \\
\hline & Deliver ingredients & $38 \%$ & 9 & 9 & 9 & 1 \\
\hline \multirow[t]{2}{*}{ Sales Markets } & Germany & $13 \%$ & 9 & 3 & 9 & 3 \\
\hline & لمa & $4 \%$ & a & ـمـ & & \\
\hline \multirow[t]{2}{*}{ Market Segments } & Premium & $4 \%$ & $T$ & 1 & 3 & 3 \\
\hline & Luxury & $4 \%$ & 0 & 0 & 1 & 3 \\
\hline \multicolumn{2}{|l|}{ Performance Fit } & $60 \%$ & $67 \%$ & $59 \%$ & $82 \%$ & $38 \%$ \\
\hline \multicolumn{7}{|l|}{ Attitude } \\
\hline Customer Orientation & Commendable & $41 \%$ & 3 & 3 & 9 & 9 \\
\hline Innovation Orientation & Distinctive & $14 \%$ & 3 & 1 & 9 & 9 \\
\hline \multicolumn{7}{|l|}{ LEacterstip on } \\
\hline Nationality & German & $14 \%$ & 9 & 9 & 9 & 9 \\
\hline \multicolumn{2}{|l|}{ Attitude Fit } & $25 \%$ & $50 \%$ & $47 \%$ & $97 \%$ & $97 \%$ \\
\hline \multicolumn{7}{|l|}{ Motivation } \\
\hline \multirow{3}{*}{ Offered Competencies } & Offer recipe & $38 \%$ & 9 & 3 & 3 & 3 \\
\hline & Gather inaredient list & $0 \%$ & - & - & - & 3 \\
\hline & Prepareanom: & & & $T$ & 5 & 3 \\
\hline Sales Markets & Access to Germany & $4 \%$ & 3 & 0 & 1 & 9 \\
\hline Market Segments & Access to all customers & $38 \%$ & 9 & 3 & 9 & 9 \\
\hline \multicolumn{2}{|l|}{ Motivation Fit } & $15 \%$ & $81 \%$ & $27 \%$ & $63 \%$ & 71 \\
\hline \multicolumn{2}{|l|}{ Partnership Fit } & $100 \%$ & $65 \%$ & $51 \%$ & $83 \%$ & 57 \\
\hline
\end{tabular}

Figure 8. Partner evaluation

ize (regional) food delivery to the customer, program a web service, process orders, produce the necessary kitchen appliances, and develop a broad base of recipes on the platform. As stated earlier, one of the core drawbacks of methods from the fields of mergers and acquisitions is that they do not provide advice on how to form bundles of companies for a specific task. As devised by Dülme (2013) in the context of strategy-compliant acquisition strategies, combinations of possible partner organizations are sought on the basis of the partner evaluation. In the following step, these combinations (i.e., bundles of organizations) will be created and prioritized (Figure 9). (The last step, sequencing, is not covered within this article.) For each bundle, a sequence in which the cooperation is to be approached is calculated. Note that each bundle contains H.A.M. (\#1 in Figure 9) and any combination of other organizations that fulfill the desired competences.

At the Heinz Nixdorf Institute (www.hni.uni-paderborn.de), software was developed to generate all possible bundles of partner organizations that fulfill the desired performance section based on the partner evaluation. The algorithm is made such that the bundling stops once all target characteristics are achieved (Sarkar, 2008), thereby allowing it to keep the bundles as small as possible. Naturally, there is a trade-off between bundle length and network effectiveness. On the one hand, the network's capabilities grow with each new partner, while on the other hand, managing the network becomes increasingly complex (Johnson \& Selnes, 2004). 


\section{Value Network Design for Innovations}

\section{Martin Kage, Marvin Drewel, Jürgen Gausemeier, and Marcel Schneider}
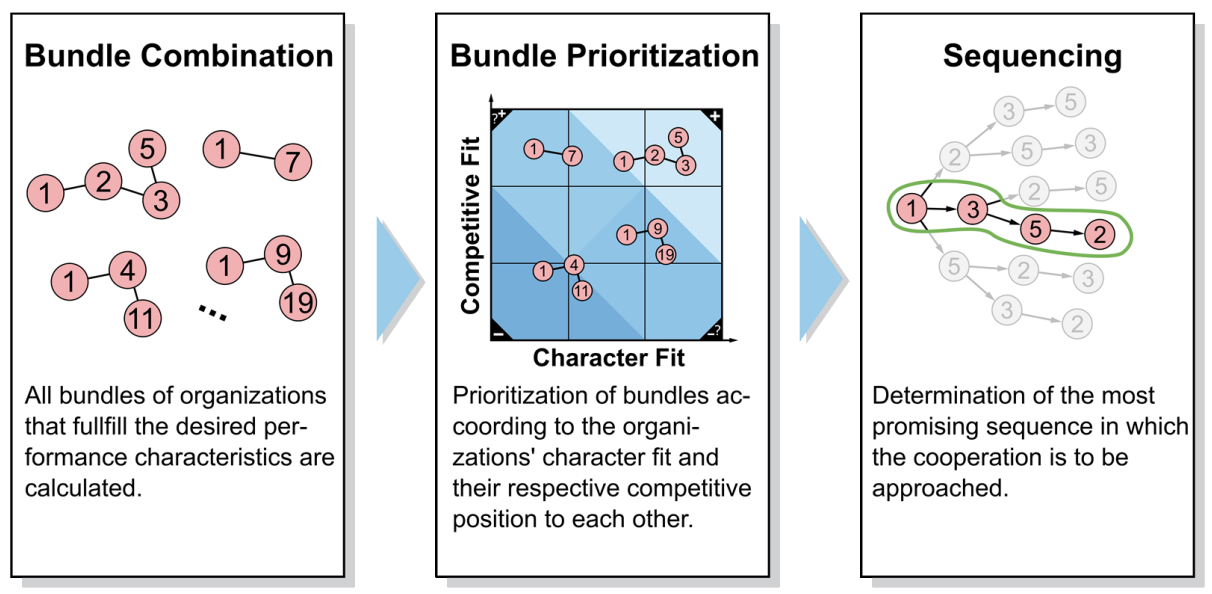

\section{Continuous Software Support}

Figure 9. Implementation planning process

The possible bundles are prioritized to identify the most promising ones, the dimensions character fit (How well do the characters of the organization match?) and competitive fit (Do the organizations compete against each other in any market?) are being used for that purpose. To determine character and competitive fits, a pairwise comparison is being applied. For instance, a bundle ex- hibits a high character fit, if the characters of all organizations within a bundle match very well. In a similar manner, the competitive fit of a bundle is being determined. An arithmetic example is provided in Figure 10. Bundles that contain any rating of 1 (i.e., two organizations exhibiting a very low character fit or competitive fit with each other) are sorted out automatically.

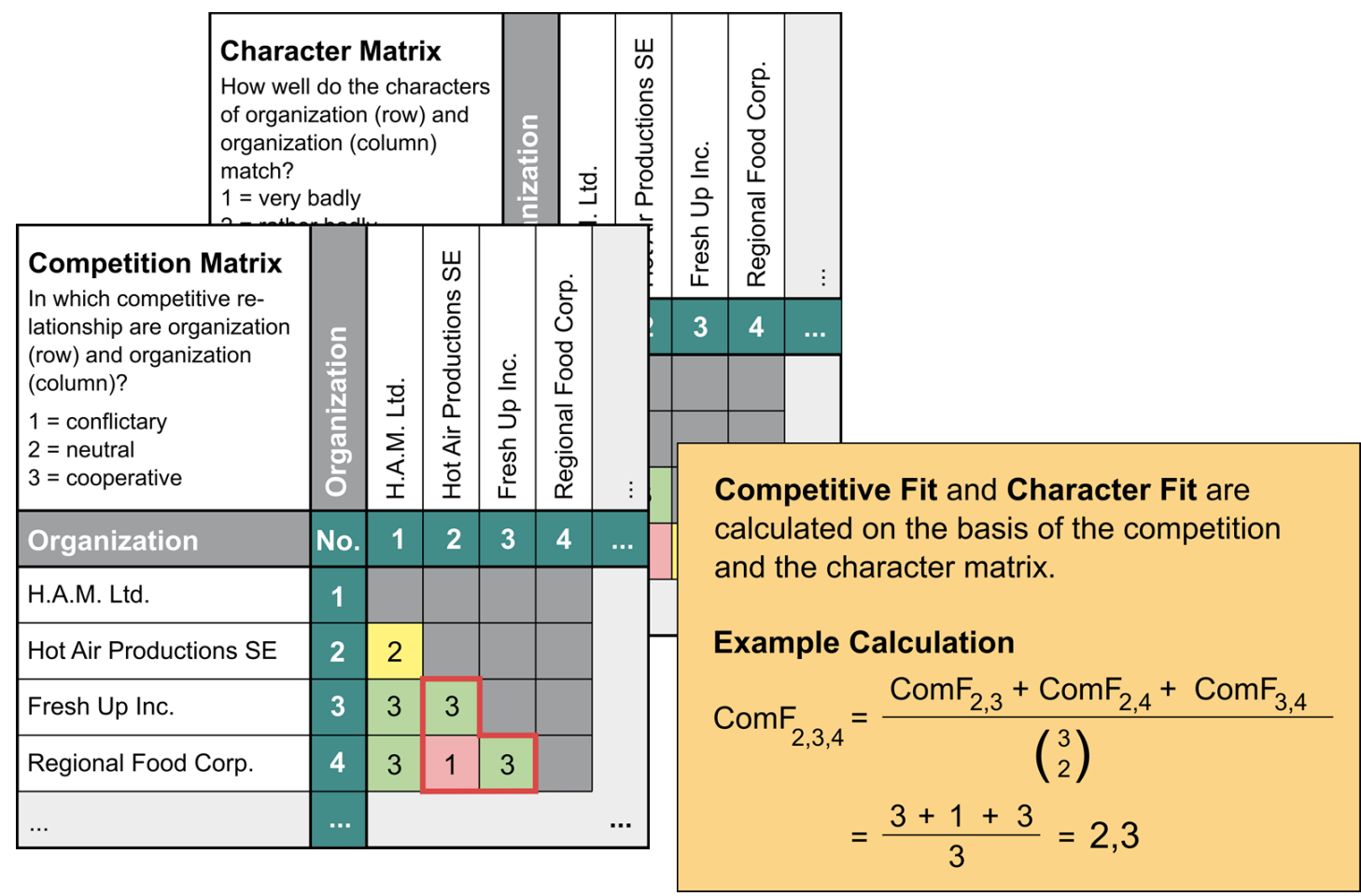

Figure 10. Character and competition matrices 


\section{Value Network Design for Innovations}

\section{Martin Kage, Marvin Drewel, Jürgen Gausemeier, and Marcel Schneider}

The chart in Figure 11 yields recommendations of actions for each bundle. The favoured bundles exhibit a high competitive fit and character fit. We thereby narrow down the number of possible bundles. Hence, no ineligible bundles are further reviewed.

In the validation project, the bundle $\{1 ; 3 ; 4\}$ scored the highest competitive and character fits (with Organization 1 being H.A.M.). Organization 3 (Fresh Up Inc.) is a startup that delivers food boxes. Their strength is the delivery of basic ingredients for a chosen amount of people and meals. Fresh Up already provides the logistics for the whole German market. Organization 4 (Regional Food Corp.) is also a startup. It focuses on the delivery of fresh and healthy ingredients of the season, which are provided by a network of regional farmers. Regional Food does not deliver basic ingredients at all times of the year, while Fresh Up does not provide fresh and healthy ingredients directly from farmers. Obviously, bundle $\{1 ; 3 ; 4\}$ would be suited well for the realization of the innovation, as the combination of both organizations provides a unique service.

Naturally, the final step of value network design would be approaching the selected organizations and setting up an intra-company business case (i.e., developing sustainable business models for each partner and formulating the value network). Therefore, it is important to guarantee that the business models of the participating organizations are compliant with each other.

As Figure 12 indicates, H.A.M. occupies the role of the recipe supplier, platform operator, and application provider. Fresh Up and Regional Food have been identified as the optimal bundle. Both occupy the role of the food vendor and logistics provider.

\section{Conclusion}

Nowadays, companies in the manufacturing industry have to face the challenges of digitalization: the need to develop "smart products" forces these companies to cut across traditional product boundaries and unleashes a new era of competition. In many cases, the know-how to develop a smart product exceeds the competences of manufacturing companies and forces them to enter cooperative relations. Usually, there are plenty of possible cooperation partners that can be permutated in various arrangements to realize an innovation. Value networks are the result of these permutations. Still, one of the core problems of cooperation planning is that, once a company starts searching for possible cooperation candidates, it will be confronted with a lack of reliable information. The information gathered will only incrementally become reliable over time as soon as the possible partners get in touch and engage in some form of collaboration.

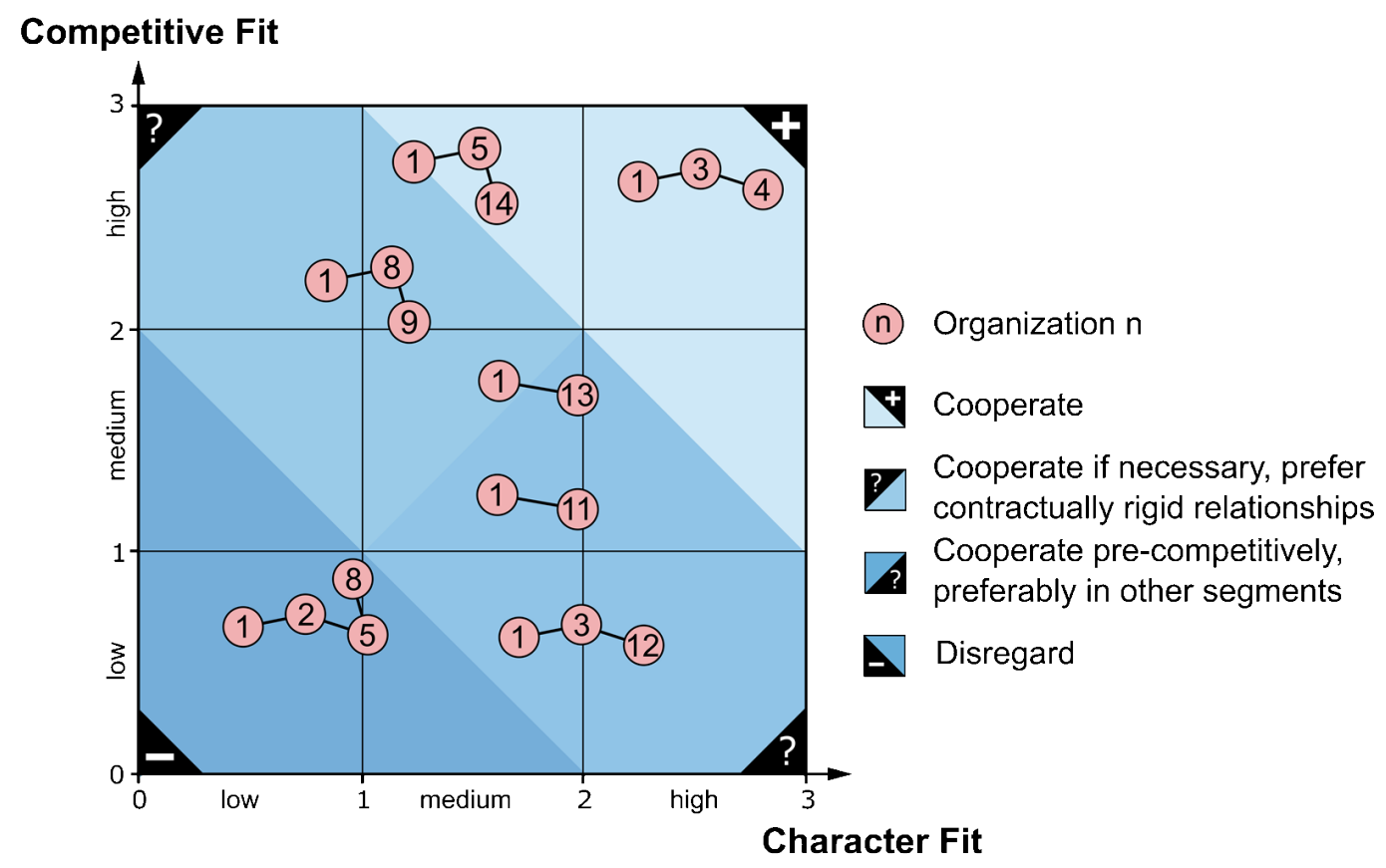

Figure 11. Bundle prioritization 


\section{Value Network Design for Innovations}

\section{Martin Kage, Marvin Drewel, Jürgen Gausemeier, and Marcel Schneider}

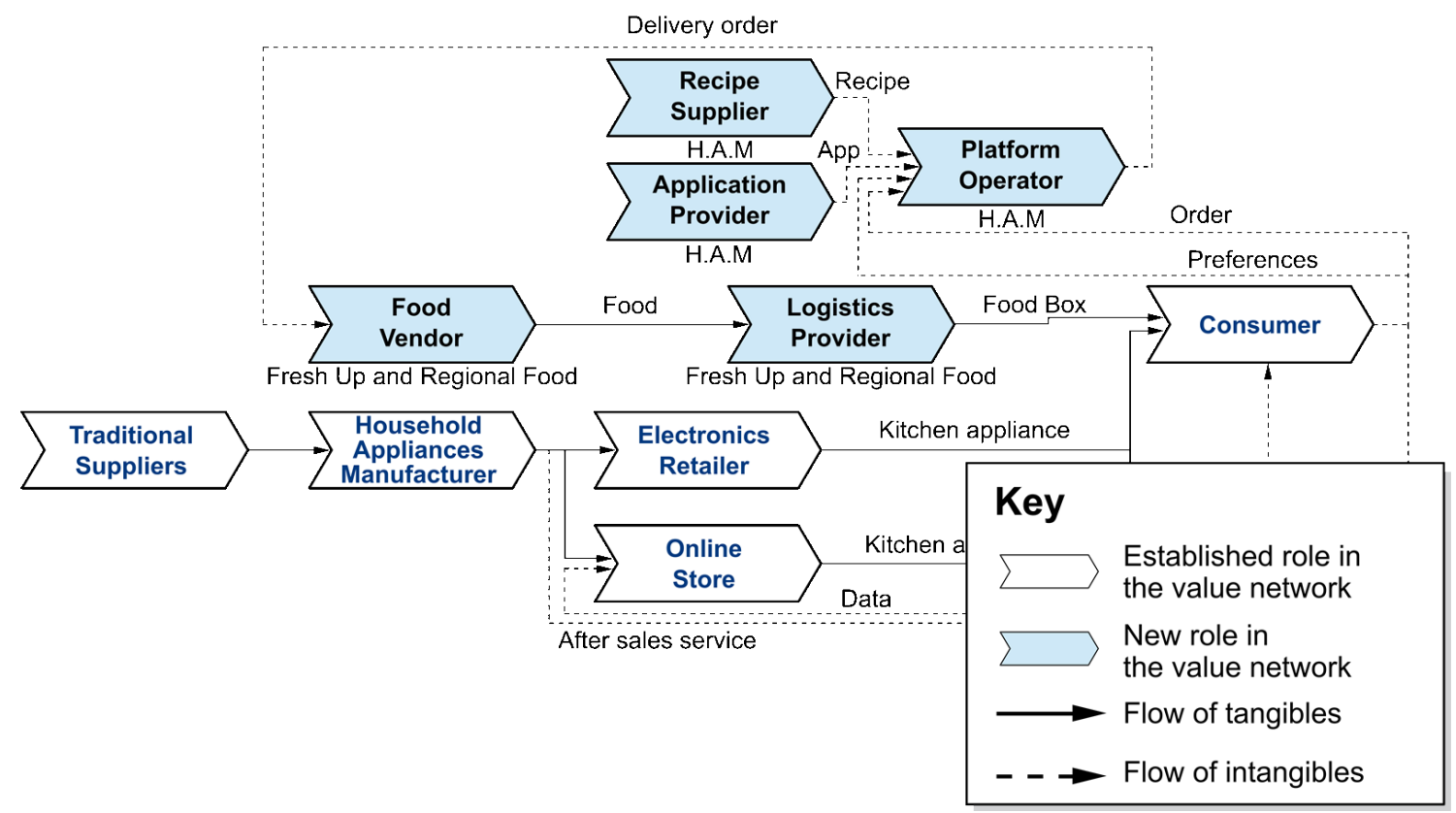

Figure 12. First draft of the value network for the Recipe $2 U$ business idea

We introduced a methodology for the design of value networks induced by an innovation (i.e., innovation pull). As a result of an innovation idea (i.e., a product, process, or business model innovation), the cooperation demand is deduced systematically. The cooperation demand determines the ideal partner profile that is used to preselect and later on evaluate potential partners. We also showed that an ideal sequence can be calculated, which denotes the order to approach partners. Eventually, a first draft of the value network can be drawn. A consistent tool support accounts for the naturally low degree of information quality. The method can be adapted once new or more concrete information becomes available. Thus, an innovation-oriented value network can be designed. From a practitioner's perspective, it is worth mentioning that the methodology does not alleviate the work of searching for possible partner organizations (i.e.. developing the so-called "long list") or rating them. However, the methodology can be used to find possible arrangements of partner companies and sensitizes for the fact that an innovation idea can be realized with, for example, either two big partners or five smaller ones. Especially when entering new markets (which implies that there are no existing long-term relationships with any of the incumbents), the methodology is a valuable extension.
One research stream which has yet to be covered from our perspective is the principle of value network push, as shown in Figure 1. Value networks themselves are usually merely used descriptively, and rarely for analytical purposes. One interesting application would be analyzing branch value networks for market entries. Once typical roles have been identified, a company can either choose to occupy one of the existing roles or deliberately position itself somewhere else in the value network and thereby create a new role, find partners for it, and cooperatively find innovations.

\section{Acknowledgements}

An earlier version of this article was presented at the 2016 ISPIM Innovation Forum in Boston, United States of America, March 13-16. ISPIM (ispim.org) - the International Society for Professional Innovation Management - is a network of researchers, industrialists, consultants, and public bodies who share an interest in innovation management. 


\section{Value Network Design for Innovations}

\section{Martin Kage, Marvin Drewel, Jürgen Gausemeier, and Marcel Schneider}

\section{About the Authors}

Martin Kage is a Research Assistant in the Strategic Product Planning and Systems Engineering group at the Heinz Nixdorf Institute in Germany. His research focus is the potential analysis of disruptive technologies, especially additive manufacturing and the strategic design of value networks. He holds an MSc in Industrial Engineering and Management from the University of Paderborn, Germany. His PhD thesis focuses on value networks as a strategic management instrument.

Marvin Drewel is a Research Assistant in the Strategic Product Planning and Systems Engineering group at the Heinz Nixdorf Institute in Germany. His research focus is strategic product planning in the context of the Internet of Things. He holds an MSc in Industrial Engineering and Management from the University of Paderborn, Germany.

Jürgen Gausemeier is a Senior Professor at the Heinz Nixdorf Institute of the University of Paderborn, Germany. His key activities are strategic product planning and systems engineering. He was speaker of the Collaborative Research Centre 614 "Self-Optimizing Concepts and Structures in Mechanical Engineering" by the German Research Foundation (DFG) and member of the German Council of Science and Humanities from 2009 until 2015. Jürgen is the initiator and chairman of the Supervisory Board of the consultant company UNITY AG. Since 2003, he has been member of "acatech - German Academy of Science and Engineering" and has been its Vice President since 2012. He is also Chairman of the Board of the Leading-Edge Cluster "Intelligente Technische Systeme Ostwestfalen-Lippe (it's OWL)", which was initiated by the Federal Ministry of Education and Research.

Marcel Schneider is a Research Assistant in the Strategic Product Planning and Systems Engineering group at the Heinz Nixdorf Institute of the University of Paderborn, Germany, as well as the Fraunhofer IEM (Department of Product Engineering). He studied Industrial Engineering and Management at the University of Paderborn, Germany. His focus is on the design of value networks, the operationalization of business models, and the digital factory.

\section{References}

Albrecht, S. 1994. Erfolgreiche Zusammenschlussstrategien - Eine empirische Untersuchung deutscher Unternehmen. Wiesbaden: Gabler Verlag.

Allee, V. 2015. Value Networks and the True Nature of Collaboration. Tampa, FL: Meghan-Kiffer Press.

Büchel, B., \& Raub, S. 2002. Building Knowledge-Creating Value Networks. European Management Journal, 20(6): 587-596. http://dx.doi.org/10.1016/S0263-2373(02)00110-X

Breschi, S., \& Malerba, F. (Eds.) 2005. Clusters, Networks and Innovation. Oxford: Oxford University Press.

Deutskens, C. 2014. Konfiguration der Wertschöpfung bei disruptiven Innovationen am Beispiel der Elektromobilität. Dissertation. Aachen: Wissenschaftlicher Verlag des Institus für Industriekommunikation und Fachmedien an der RWTH Aachen.

Dülme, C. 2013. Entwicklung einer Methodik zur Planung strategiekonformer Unternehmensübernahmen. Research Project: Faculty for Mechanical Engineering, University of Paderborn.

Echterhoff, N. 2014. Systematik zur Planung von Cross-IndustryInnovation. Dissertation. Paderborn: HNI-Verlagsschriftreihen.

Ehrlenspiel, K., Kiewert, A., Lindemann, U., \& Mörtl, M. 2005. Kostengünstig Entwickeln und Konstruieren. Berlin: Springer Verlag.

Esche, d.v. J., \& Henning-Thurau, T. 2014. German Digitalization Consumer Report 2014. Münster: University of Münster and Roland Berger.

Fjeldstad, Ø., \& Ketels, C. 2003. Competitive Advantage and the Value Network Configuration: Making Decisions at a Swedish Life Insurance Company. Long Range Planning, 38(2): 109-131. http://dx.doi.org/10.1016/j.lrp.2006.05.001

Gausemeier, J., Amshoff, B., Dülme, C., \& Kage, M. 2014. Strategische Planung von Marktleistungen im Kontext Industrie 4.0. In Gausemeiser, J. (Ed.): Vorausschau und Strategieplanung, Band 334. Paderborn: HNI-Berlagsschriftenreihe.

Gartner. 2015. Gartner Hypecycle for Emerging Technologies. Gartner: August 18, 2015. Accessed December 27, 2015: http://www.gartner.com/newsroom/id/3114217

Grandstad, O., \& Sjolander, S. 1990. Managing Innovation in MultiTechnology Corporations. Research Policy, 19(1): 35-60. http://dx.doi.org/10.1016/0048-7333(90)90033-3

Hermes, M. 1995. Eigenerstellung oder Fremdbezug neuer Technologie. Dissertation. Kiel: Fakultät für Wirtschaftswissenschaften, Universtiy of Kiel.

Heubach, D., Slama, A., \& Rüger, M. 2008. Der Technoliogieentwicklungsprozess. In Bullinger, H. (Eds.), Fokus Technologie - Chancen erkennen, Leistungen entwickeln: 13-43. Munich: Carl Hanser Verlag.

Holmstrom, B., \& Roberts, J. 1998. Boundaries of the Firm Revisited. Journal of Economics and Perspectives, 4(12): 73-94. http://dx.doi.org/10.1257/jep.12.4.73

Hui, G. 2014. How the Internet of Things Changes Business Models. Harvard Business Review, 92(7/8): 1-5. 


\section{Value Network Design for Innovations}

\section{Martin Kage, Marvin Drewel, Jürgen Gausemeier, and Marcel Schneider}

Jansen, S. 2001. Mergers \& Acquisitions. Munich: Gabler Verlag.

Johnson, M. D., \& Selnes, F. 2004. Customer Portfolio Management: Toward a Dynamic Theory of Exchange Relationships. Journal of Marketing, 68(2): 1-17.

http://dx.doi.org/10.1509/jmkg.68.2.1.27786

Kraus, R. 2005. Strategisches Wertschöpfungsdesign. Wiesbaden: Deutscher Universitätsverlag.

Kühnapfel, J. 2014. Nutzwertanalysen in Marketing und Vertrieb. Wiesbaden: Gabler Verlag.

Kumar, N. 2004. Marketing as Strategy: Understanding the CEO`s Agenda for Driving Growth and Innovation. Cambridge, MA: Harvard Business Review Press.

Möller, K. 2006. Wertschöpfung in Netwerken. Munich: Vahlen Verlag.

Müller-Stevens, G., \& Lechner, C. 2005. Strategisches Management: Wie strategische Initiativen zum Wandel führen. Stuttgart: Schäffer-Pöschel Verlag.

Normann, R., \& Ramirez, R. 1993. Designing Interactive Strategy. Harvard Business Review, 71(4): 54-74.

Picot, H. (Ed.) 2002. Handbook of International Mergers and Acquisitions: Preparation, Implementation and Integration. Basingstoke, UK: Palgrave Macmillan.

Porter, M. E. 1980. Competitive Strategy: Techniques for Analyzing Industries and Competitors. New York: The Free Press.
Porter, M. E., \& Heppelmann, J. E.. 2014. How Smart, Connected Products Are Transforming Competition. Harvard Business Review, 92(11): 64-88.

Rübbelke, R. 2016. Systematik zur innovationsorientierten Kompetenzplanung. Dissertation. Paderborn: HNI Verlagsschriftreihe.

Sattler, A., \& Broll, H-J., \& Müller-Hermann, H-J., \& Olbert, G. 1992. Joint Ventures und Kooperation - Chance für die 90er Jahre. Kontakt \& Studium. Band 363. Ehningen bei Böblingen: Expert Verlag.

Sell, A. 1994. Internationale Unternehmenskooperation. Munich: R. Oldenbourg Verlag.

Sakar, S. 2008. Dynamics of Open Innovation in the Food Industry. Trends in Food Science \& Technology, 19(11): 574-580. http://dx.doi.org/10.1016/j.tifs.2008.09.006

Weber, Y. 1996. Corporate Cultural Fit and Performance in Merges and Acquisitions. Human Relations, 49(9): 1181-1202. http://dx.doi.org/10.1177/001872679604900903

Yassine, A., \& Braha, D. 2003. Conccurent Engineering and the Design Structure Matrix Method. Research and Applications, 11(3): 165-177. http://dx.doi.org/10.1177/106329303034503

Zentes, J., Swoboda, B., \& Morschett, D. 2003. Kooperationen, Allianzen und Netzwerke. Wiesbanden: Gabler Verlag.

Citation: Kage, M., Drewel, M., Gausemeier, J., \& Schneider, M. 2016. Value Network Design for Innovations: Developing Alternative Value Network Drafts. Technology Innovation Management Review, 6(7): 21-33. http://timreview.ca/article/1002 